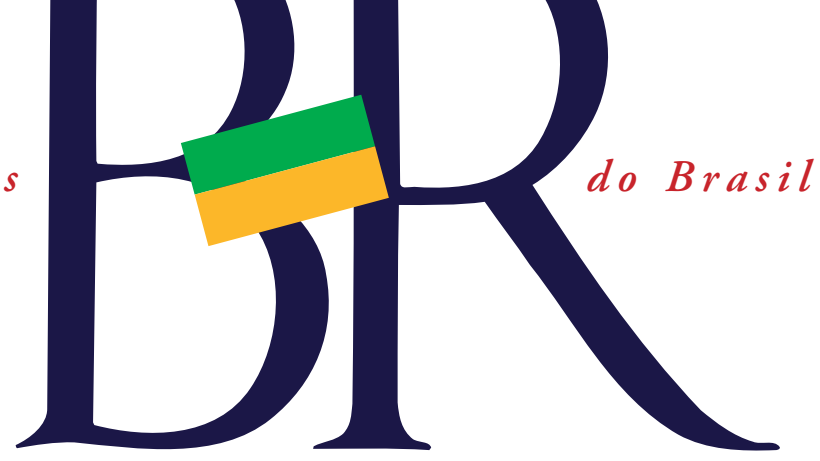

PATENTES DE SOFTWARE EM QUESTÃO

A luta contra as patentes de software, uma das principais bandeiras do Movimento do Software Livre, motiva grandes discussões. A norte-americana Free Software Foundation, por exemplo, mantém a campanha "End software patents", porque percebe as patentes como uma ameaça. É inviável para um programador independente, por exemplo, desenvolver um software livre, pesquisar e estar ciente de todas as patentes que podem incidir sobre seu trabalho. 0 texto descritivo dessas patentes é vago, de forma a cobrir uma grande área de atuação, o que cria, de fato, uma área de risco. A carta aberta também tratou do pregão eletrônico recentemente lançado pela Caixa Econômica Federal (N. 116/7066-2012 - Gilog/ BR) para aquisição de softwares proprietários da Microsoft. 0 pregão evidencia, diz o documento, que o uso do software livre no governo federal tem um de seus principais pilares ameaçado. A CEF, até recentemente, era grande usuária de software livre, além de desenvolvedora, com soluções inovadoras disponibilizadas à comunidade. 0 acesso à íntegra da carta aberta à presidenta Dilma Rousseff está no link: http:// softwarelivre.org/fisl13/noticias/ carta-a-dilma
Reprodução Humana

\section{Cresce demanda por tratamento de infertilidade, mas 0 acesso é ainda caro e seletivo}

Em 1978 nascia a inglesa Louise Brown, primeira criança concebida a partir de embrião gerado em laboratório, ou o primeiro bebê de proveta, como ficou conhecida. Tal conquista médica serviu de esperança a inúmeros casais que sonhavam com filhos, mas que tinham dificuldades reprodutivas. Em mais de três décadas, essa prática médica, que passou a ser chamada de reprodução (humana) assistida, não parou de se desenvolver e é indicada a um número cada vez maior de pacientes.

A cada ano ocorrem cerca de 2.500 procedimentos de reprodução assistida no Brasil, equivalente a um crescimento anual de 5 a $10 \%$ nos últimos cinco anos, informa o médico Édson Borges Júnior, vice-presidente da Sociedade Brasileira de Reprodução Assistida e diretor do Centro de Fertilização Assistida Fertility, de São Paulo. O novo estilo de vida dos casais modernos, que adiam a gestação, é um dos motivos para esse cenário de maior busca por tratamento reprodutivo. "Antigamente as mulheres tinham filhos mais cedo,
Reprodução

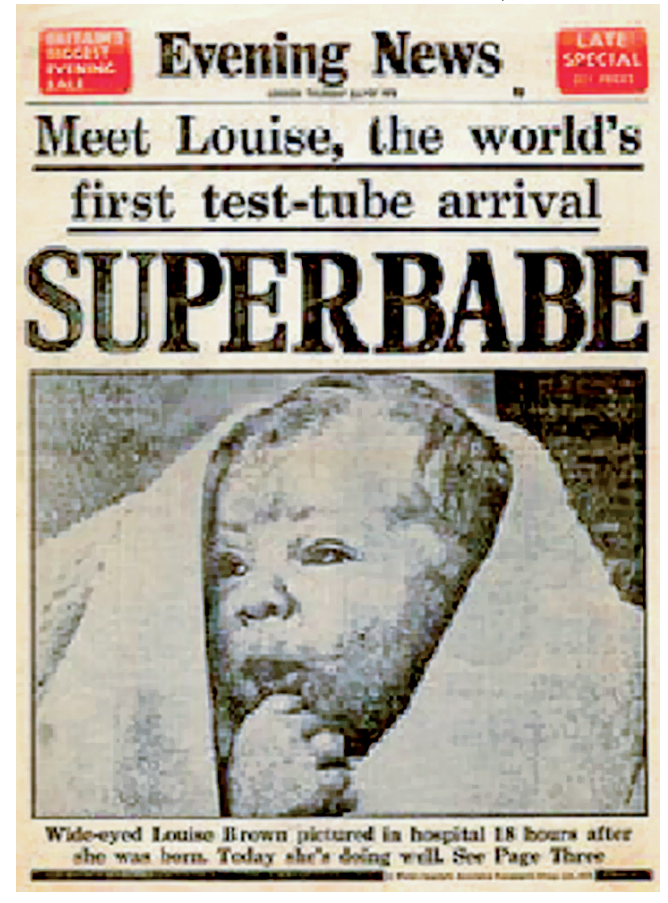

Manchete sobre bebê de proveta em 1978

entre os 20 e 30 anos; hoje, retardam a maternidade, principalmente por causa de tarefas e compromissos profissionais, o que altera a fertilidade e reduz a possibilidade de engravidar", conta Ana Carolina Japur de Sá Rosa e Silva, docente do Departamento de Ginecologia e Obstetrícia da Faculdade de Medicina de Ribeirão Preto da Universidade de São Paulo (FMRP-USP). Ela explica que, ao contrário dos homens (que produzem espermatozoides periodicamente), as mulheres possuem um número finito de gametas, cujo número diminui com o passar do tempo. "As pacientes que buscam o serviço de reprodução assistida pela primeira 
vez têm em média 38 anos, e depois querem ter outro filho aos 40 , idade em que a quantidade de óvulos já declinou bastante", relata a médica.

No quesito idade, muitas vezes a reprodução assistida tem papel pouco esperançoso. "Em geral, a chance média da reprodução assistida ser bem sucedida é de 30 a $40 \%$ nos casais até 40 anos; a partir dessa idade, essa chance cai para $20 \%$, chegando a menos de 5\% aos 42 anos", esclarece Rui Alberto Ferriani, docente e médico responsável pelo setor de Reprodução Humana do Hospital das Clínicas (HC) da FMRP.

A fertilidade masculina também sofre alteraçōes: "hoje, quando se analisa um espermograma (exame usado para avaliar a qualidade do sêmen), dificilmente encontra-se 90, $100 \mathrm{mi}$ lhões de espermatozoides por mililitro de sêmen, o que era absolutamente normal há 30 anos", avalia Mário Cavagna, secretário da Comissão $\mathrm{Na}$ cional de Reprodução Humana da Federação Brasileira de Ginecologia e Obstetrícia (Febrasgo). Como exemplo causal dessa alteração, ele acusa o consumo constante e prolongado de produtos com substâncias que comprovadamente interferem na saúde reprodutiva, como os agrotóxicos.

Há vários outros pontos a se levar em conta no modo como se comporta a sociedade contemporânea, como "a presença de doenças sexualmente transmissíveis e aumento da obesidade", que elevam o risco de infertili- dade, como descreve Carlos Alberto Petta, diretor do Centro de Pesquisas em Saúde Reprodutiva de Campinas e coordenador do Centro de Reprodução Humana do Hospital Sírio Libanês. Existe também o fator psicológico. "Muitos casais acreditam que a partir do momento em que decidem gerar descendentes, a gravidez ocorrerá, no máximo, em 2 a 3 meses, eficam extremamente ansiosos em não ter êxito no tempo em que imaginavam", conta Liliana Seger, psicóloga clínica e professora de pós-graduação do curso de reprodução humana do Instituto Sapientae.

FILA DE ESPERA Não existem números oficiais indicativos do número de casais brasileiros com problemas reprodutivos. Estima-se, porém, que, mundialmente, hoje " 15 a $20 \%$ dos casais tenham dificuldade para gerar um filho em algum momento de sua idade reprodutiva”, afirma Ana Carolina. O que se sabeéque a assistência reprodutiva brasileira aos casais inférteis ainda é muito pequena. $\mathrm{O}$ cenário nacional é de "uma enorme demanda reprimida: existe um grande número de pacientes que necessitam de reprodução assistida e não conseguem ter acesso a clínicas especializadas, sejam elas particulares (preços muito altos, de $\mathrm{R} \$ 15$ mil a $\mathrm{R} \$ 20$ mil) ou oferecidas em serviços públicos, que não comportam a quantidade de casais que os procuram", explica Cavagna, que também é diretor da Divisão de Re- produção Humana do Hospital Pérola Byington, única instituição em que o protocolo completo de reproduçáo assistida é totalmente custeado com verba pública, da Secretaria de Saúde do Estado de São Paulo. No entanto, "para atender a procura, o hospital teria que realizar 2 mil procedimentos por ano e só conseguimos fazer 300; há uma fila de espera de quatro anos para novos casos", lamenta. Apesar da Portaria 426/GM (2005) "instituir, no âmbito do Sistema Único de Saúde (SUS), a Política Nacional de Atenção Integral em Reprodução Humana Assistida, a ser implantada em todas as unidades federadas", como escrito no próprio documento, ela nunca foi implementada. Atualmente, o que se tem de contribuição do SUS é algo pequeno e pontual. No HC da FMRP, por exemplo, "o SUS não financia os procedimentos de reprodução assistida, embora esta seja uma aspiração de todos os serviços públicos que trabalham com isso", conforme notificou a superintendência do hospital. O panorama, porém, pode melhorar. Uma comissão de parlamentares está tentando uma audiência pública com a presença de representantes do Ministério da Saúde e de importantes sociedades brasileiras de reprodução para discutir o acesso realmente integral aos procedimentos de reprodução assistida por meio do SUS.

Daniel Blasioli Dentillo 